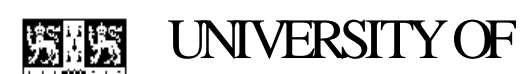 \\ CAMBRIDGE
}

\section{Cambridge Working Papers in Economics}

Addressing self-disconnection among prepayment energy consumers: A behavioural approach

Marta Rocha, Michelle Baddeley and Michael G. Pollitt 
Addressing self-disconnection among prepayment energy consumers: A behavioural approach

Marta Rocha, Michelle Baddeley and Michael G. Pollitt

November 2013

CWPE 1353 \& EPRG 1328 


\title{
Addressing self-disconnection among prepayment energy consumers: A behavioural approach
}

\author{
EPRG Working Paper 1328
}

Cambridge Working Paper in Economics 1353

\section{Marta Rocha, Michelle Baddeley and Michael G. Pollitt}

\begin{abstract}
This paper uses insights from the study of self-control in decision-making to remedy the problem of self-disconnection among energy prepayment consumers. Self-disconnection happens when consumers exhaust all available credit in their meter and are left without supply of energy. This has serious consequences for the wellbeing of consumers and may increase firms' costs. We design a mechanism composed of a commitment contract and a reminder in order to minimize the number of self-disconnections. We empirically assess this mechanism by examining (1) the determinants of self-disconnection and (2) the choice of different commitment contracts. We show that self-control plays a role in self-disconnection and we are able to identify, in our sample, those consumers who benefit from a commitment contract. Moreover, we find a demand for commitment and an opportunity to save among those consumers who need a commitment contract.
\end{abstract}

Keywords Commitment contract; Self-control; Prepayment meter; Self-disconnection; Reminder

JEL Classification $\quad$ D03, D12, D91

Contact mr577@cam.ac.uk

Publication November 2013

Financial Support EPRG 


\title{
Addressing self-disconnection among prepayment energy consumers: A behavioural approach ${ }^{1}$
}

\author{
Marta Rocha ${ }^{\dagger}$, Michelle Baddeley ${ }^{\dagger \dagger}$ and Michael G. Pollitt ${ }^{\dagger \dagger \dagger}$
}

November 2013

\begin{abstract}
This paper uses insights from the study of self-control in decision-making to remedy the problem of self-disconnection among energy prepayment consumers. Self-disconnection happens when consumers exhaust all available credit in their meter and are left without supply of energy. This has serious consequences for the wellbeing of consumers and may increase firms' costs. We design a mechanism composed of a commitment contract and a reminder in order to minimize the number of selfdisconnections. We empirically assess this mechanism by examining (1) the determinants of self-disconnection and (2) the choice of different commitment contracts. We show that self-control plays a role in selfdisconnection and we are able to identify, in our sample, those consumers who benefit from a commitment contract. Moreover, we find a demand for commitment and an opportunity to save among those consumers who need a commitment contract.
\end{abstract}

JEL classification: D03, D12, D91.

Keywords: Commitment contract; Self-control; Prepayment meter; Self-disconnection; Reminder.

\footnotetext{
${ }^{1}$ The authors wish to thank British Gas for their excellent collaboration and great support, in particular we wish to thank Louise Rhodes, Patrick Wilson, and Matthew Pearson. We also thank Melvyn Weeks, Steffen Hoernig, Thomas Greve, and Philip Doran for their thoughtful comments. Marta Rocha acknowledges the financial support by FCT (Fundação para a Ciência e a Tecnologia). The opinions in this paper reflect those of the authors alone and do not necessarily reflect those of any other individual or organisation. 


\section{Introduction}

Research in economics and psychology suggests that most choices involve intertemporal trade-offs between immediate and delayed costs or benefits (Frederick et al. 2002). In order to evaluate such trade-offs, decision makers compare the costs and the benefits that occur at different times. However, people can be impatient in the sense that they like to enjoy immediate rewards and to defer costs (O’Donoghue and Rabin 1999). Strotz (1956) was the first to model impatience for near-term trade-offs rather than for future ones, modelling it as a commitment device. He showed that under exponential discounting preferences are time consistent, but under non-exponential discounting agents may prefer to constrain their own choices.

Self-control plays an important role in explaining inconsistencies for the future over time and across activities (Lowenstein 2000). People with high levels of self-control are able to stay on diets, exercise regularly, and to lead their lives within their means, whereas those that lack self-control end up not achieving their aims (Laibson 1997). In order to constrain future choices and to obtain a desired outcome, people impose commitment devices that facilitate the achievement of goals (Brocas et al. 2004; Bryan et al. 2010). It has been shown that commitment devices are effective in improving performance in school (Ariely and Wertenbroch 2002), in saving money (Ashraf et al. 2006; Benartzi and Thaler 2004), in the context of addictions (Bernheim and Rangel 2004), etc.

Prepayment metering is an interesting case to study intertemporal trade-offs. Prepayment is a payment method where the payment is made before the actual consumption; that is, consumers have to pay for electricity and/or gas (immediate costs) before they consume it (delayed benefits). Moreover, consumers must plan in advance their future consumption. This planning, or lack of it, may lead to self-disconnection, which happens when consumers exhaust all available credit in their meter and are left without supply of energy for a certain period.

Self-disconnection has serious consequences for the wellbeing of consumers, such as lack of heating; impacts on food preparation; leisure and psychological impacts, e.g. shame or loss of self-esteem (Consumer Focus 2010). Likewise, self-disconnection generates costs for the energy suppliers since it may contribute to lower energy consumption, higher debt levels, and higher costs related to reconnection of energy supply. 
The aim of this paper is to propose a mechanism that minimizes the number of selfdisconnections through commitment and awareness. This paper has implications not only for the more efficient use of prepayment in energy, but has also implications for poverty. In fact, self-disconnection is especially pronounced among low-income households and has been linked to fuel poverty (Brutscher 2012b; O’Sullivan 2013). Fuel poverty is usually defined as the inability to keep an adequate level of warmth on $10 \%$ of household income and has been regarded as a likely contributor to increased winter mortality rates (O'Sullivan et al. 2013). If we find a mechanism that minimizes the number of self-disconnections, then we can contribute to a better energy comfort for those households who fall in the category of fuel poor, reducing the negative consequences of fuel poverty.

First, we design a mechanism that induces higher rates of savings committed to energy consumption and that decreases the likelihood of consumers to self-disconnect. Consumers differ in their degree of self-control and in their willingness to accept a commitment device. The energy supply firm does not know the different degrees of selfcontrol amongst consumers and so needs to target consumers effectively. The mechanism is composed of a commitment contract and an energy consumption reminder in order to account for the heterogeneity of consumers and their private information. We propose a commitment contract for consumers who lack self-control but their awareness makes them sophisticated enough to engage in such a contract, and a feedback/reminder to those consumers who are not aware of their lack of self-control.

Second, we empirically examine the determinants of self-disconnection and the choice of different commitment contracts using data from a representative survey that we have designed for this purpose. The survey was applied to a subset of British Gas customers who use a gas prepayment meter. British Gas is one of the largest retailers in the UK, providing service to approximately 15.9 million energy households.

We find that self-control problems play a role in self-disconnection. We are able to identify those consumers who would benefit from a commitment contract. Moreover, we show that there is a demand for commitment and saving opportunities among consumers. These findings demonstrate that there is a scope to introduce a commitment contract. The prepayment meter can be used as a flexible self-commitment device and in fact a significant share of consumers use the prepayment meter as a device to control energy expenses. However, prepayment meters alone cannot prevent self-disconnection completely. This emphasizes the need for a commitment contract that increases the control over energy expenses. Overall, we show that there is an interest over the different commitment saving 
contracts, and that a significant share of consumers would prefer to smooth their energy expenditures if a commitment contract enabled them to do so.

\section{Background on prepayment energy}

Prepayment consumers insert credit into their meters by the use of a key or card that is then used or spent when electricity or gas is consumed in the home. This allows the consumer to decide the amount of energy to be consumed beforehand, as happens commonly with mobile phone services.

Prepayment meters (PPMs) emerged as a mean of offering indebted domestic consumers the ability to pay their energy bills. Countries such as UK, South Africa, Mozambique, Canada, Australia, among others, offer this type of payment in the "energy sector". In UK, the number of PPM consumers increased, by 2012, to around 4.2 million household electricity consumers $(15.5 \%$ of the total) and 3 million household gas consumers (13.3\% of the total) (Ofgem 2012).

One important feature of PPMs is that, when the credit is exhausted, the supply of energy can be interrupted. In a stricter definition, self-disconnection happens when the consumer has exhausted all the available credit, including the emergency credit. The emergency credit is a fixed value (usually $£ 5$ in UK) of gas or electricity that is made available, at no extra cost, when consumers run out of credit and was created to overcome self-disconnection. However, other alternatives are also offered. One example is friendly credit - certain periods over the day in which suppliers do not disconnect whatever the consumer's usage or credit status. These options give more time for consumers to top up their card.

Different reasons have been given in order to explain self-rationing and selfdisconnection: inconvenience/transport costs, forgetting to top up, financial constraints or coordination issues (Brutscher 2012b; O'Sullivan et al. 2013; Consumer Focus 2010). In situations in which the reasons are a lack of opportunity to go to an outlet; forgetting to top up; or coordination issues within the household - options like emergency credit or friendly credit are good solutions. Conversely, if we consider financial constraints, identified by Brutscher (2012b) as the main driver of self-disconnection, such solutions may just postpone the problem rather than fix it. On the one hand, it can provide more credit flexibility by 
providing additional help for those who do not have money available, but on the other hand, it does not help consumers with more severe problems and/or who lack of self-control.

Self-disconnection implies that households opt to have discrete jumps in energy consumption rather than smoothing consumption throughout the year. Brutscher (2012b) analyses this puzzle and argues that a possible explanation is preference reversals (usually associated with self-control problems) that end up affecting consumers' ability to save. In the UK, self-disconnection happens mostly during the autumn/winter for gas consumption since energy expenditure tends to be greater than in the spring/summer due to heating. During the winter, consumers might realize that they need to save in order to avoid self-disconnection, but as soon as the summer arrives they have a different set of preferences. Those households who exhibit impatience during the summer can fail to have the sufficient liquidity to purchase enough credit during the winter, which affects their tendency to self-disconnect.

Building on Brutscher's (2012b) findings, we propose a mechanism composed of a commitment contract and a reminder to induce higher rates of savings and consequently, decrease the likelihood of self-disconnection.

\section{A mechanism to minimize self-disconnection}

We start by analysing the type of consumers that we need to target in order to reduce selfdisconnections. In the literature on self-control there is a major distinction between "sophisticated" and "naïve" agents. "Sophisticated" agents are aware of their lack of future self-control whereas "naïve" agents are unaware (O'Donoghue and Rabin 1999, 2001) 2 . Agents unaware of their self-control problems will repeatedly procrastinate believing that they will act tomorrow. This heterogeneity among agents complicates the incentive design since optimal incentives differ for different types of agents. "Sophisticated" agents will easily accept a commitment contract. "Naïve" agents are less likely to accept an energy commitment contract since they have incorrect perceptions about future behaviour. As Brutscher (2012a) points out household energy, like all household expenditure, may involve complicated family dynamics where the presence of a commitment device may allow a "sophisticated" agent within the family to prevent a "naïve" agent from acting inconsistently

\footnotetext{
${ }^{2}$ O'Donoghue and Rabin $(1999,2001)$ and Laibson (1997) analyse the existence of cognitive behavioural issues that lead for a need of a commitment device through a (quasi)-hyperbolic model. Other important works are based on temptation (Gul and Pesendorfer 2001), dual-self (Fudenberg and Levine 2006) and limited attention (Karlan et al. 2010).
} 
with family resources, e.g. a husband spending money on summer time other than allowing the wife to save for winter fuel. A firm serving a mixed group of agents (consumers) does not usually know the degree of self-control of the individual consumers and so it needs to offer a different type of incentive for the naïve. In order to induce these consumers to accept a commitment contract or at least to increase their level of awareness, we propose an energy consumption reminder.

Overall, the consumers that we wish to target (1) are more likely to have self-control issues as opposed to consumers that do not act inconsistently; (2) can afford the spare cash required in order to increase their savings; and (3) have higher personal self-disconnection or self-rationing costs than benefits, i.e. they, together with the firm, should benefit from minimizing self-disconnection.

\subsection{Commitment contract}

The ideal commitment contract to offer to energy consumers would be one that provides maximal consumption smoothing. However, there are challenges when developing a contract that involves a commitment product.

First, one needs to consider the trade-off between commitment and flexibility. As pointed out in Ashraf et al. (2003), individuals demand highly liquid saving devices but they also need a certain degree of commitment. Thus, there is a trade-off between flexibility and commitment that will vary according to the customer's self-control.

Second, we need to consider whether there is a concern about exploitation of consumers. From a consumer perspective, if a household accepts the commitment contract offered by a firm then it is because it will benefit from it, otherwise it would not accept it. Interestingly, in the present case, a commitment contract, if successful, can decrease costs associated with self-disconnection for the consumers (in terms of energy discomfort) and the firm (in terms of the costs of dealing with disconnection/debt collection).

Based on these concerns, we propose four types of commitment contracts that can work in the context of prepayment energy. As in Beshears et al. (2011), we consider different contracts with different degrees of flexibility and saving targets (see Table 1). The essence of these contracts is straightforward: households commit to allocate a portion of each top-up into savings to use in future energy expenditure. In the contracts' design, we have assumed two periods: period 0 corresponds to the spring/summer where the commitment is made, and 
period 1 corresponds to the autumn/winter where self-disconnection is reduced. The contracts here proposed are the following ones.

Regular payments throughout year: Based on a summary of the previous year's consumption, the customer agrees to an equal weekly/monthly amount and commits to a payment schedule through the year. This contract implies a significant loss of flexibility.

Voluntary savings target: The customer chooses a target amount that they feel comfortable/confident about saving. The customer is responsible for meeting this target and it is up to them whether it is achieved each month. The credit saved can be used to offset winter consumption. The customer is free to choose how much to save in each week, but postponing savings is allowed.

Ad-hoc extra payments: The customer makes additional payments as and when they can afford to do so. The customer would not have to nominate a target for savings, but the more that is saved the more winter consumption would be offset. This is the plan that offers the most flexibility of all commitment contracts, although it is not a real commitment, only an awareness device.

Summer fixed extra payments: The customer commits to additional fixed payments just during summer months. These additional payments could be calculated on the basis of wintertime gas consumption in the previous year, not necessarily equal payments throughout the year. The extra payments would be used to cover higher gas payments in the wintertime.

Table 1 shows the main differences in terms of flexibility and saving target for the four types of commitment contract. Flexibility is either low or medium because in all contracts, the consumer has to insert extra credit in the meter that can only be used for gas or electricity expenses. This is in contrast with the energy consumption reminder that, as we will discuss in the next section, has a high degree of flexibility and no-predefined saving target.

Table 1. Main features of the commitment contracts

\begin{tabular}{l|cccc}
\hline \hline & $\begin{array}{c}\text { Regular payments } \\
\text { throughout year }\end{array}$ & $\begin{array}{c}\text { Voluntary savings } \\
\text { target }\end{array}$ & $\begin{array}{c}\text { Ad-hoc extra } \\
\text { payments }\end{array}$ & $\begin{array}{c}\text { Summer fixed } \\
\text { extra payments }\end{array}$ \\
\hline Flexibility & Low & Medium & Medium & Low \\
Saving target & Yes (set by the firm) & $\begin{array}{c}\text { Yes (set by the } \\
\text { consumer) }\end{array}$ & No & $\begin{array}{c}\text { Yes (set by the } \\
\text { consumer) }\end{array}$ \\
\hline \hline
\end{tabular}

In order to avoid attrition, the following restriction could be imposed: "Savings can only be consumed in the following period". This can be done, if feasible in both technical and regulatory terms, through a second card used to insert and lock the savings or via an online 
"commitment store", e.g. stickk.com. If consumers need to withdraw their savings, then they need to contact the firm. By creating more transaction costs, consumers have the incentives to break the commitment only for reasons such as unexpected shocks as opposed to procrastination or impulse/temptation.

It could be that fixing an amount of credit in the prepayment card is not possible for technical reasons or simply not allowed by the authorities. In this case, one can minimize the number of withdrawals before time through a reward/incentive. Actually, in some of the proposed contracts, a minimum saving requirement is explicitly assumed. In order to emphasize the importance of such a requirement, a reward to save can be introduced. In the beginning of period 0 , the consumer chooses a "fixed" goal amount of savings to accumulate during period 0 . If, at the beginning of period 1 , the goal has been reached, then the reward is given.

We can also impose, if necessary, a further requirement: no self-disconnection. This can be achieved through the use of a reward that is offered to the customer if they do not selfdisconnect during the winter.

Note that these rewards should not be very high/attractive for three reasons. First, consumers may just accept because the effective price of energy has been changed, rather than because of a "behavioural" change. Second, we want to ensure that those consumers whose costs (in terms of energy discomfort) are higher than the benefits of self-disconnection (in terms of extra money saved from not consuming energy during a certain period) are targeted to receive the commitment contract. Third, the reward implies costs to the firm that should not be exceeded by the benefits associated with the lower number of selfdisconnections, otherwise the firm will not have an incentive to offer a commitment contract.

A further concern that may arise regards competition issues and lock-in effects (i.e. when the firm makes it extremely hard for the customers to leave them). Given that the consumers are free to choose their type of contract, if the firm continues offering the conventional prepayment method (among others), then the consumers are always free to switch type of contract, besides being able to switch firm.

\subsection{Reminder/Feedback on consumption}

We suggest a reminder or feedback in order to attract consumers who do not accept a commitment contract due to their self-control unawareness. The idea is that the energy supply firm would increase consumers' awareness regarding the need to top up regularly. 
So far, we have assumed that self-disconnection is associated with an incomplete task, where this task is the accumulation of savings for future energy expenditure. A commitment device is used to increase the chances of successfully completing the task. However, perhaps the problem is that, in certain periods, consumers forget that their energy expenditure in the winter is greater than in the summer, which, leads to over consumption or under saving. Then when winter arrives, the consumer faces the second-best option of reducing energy consumption. It may also be that consumers do not recognize their future expenditure because they do not value heating as much as their future self does and so they assume that energy expenditure will be roughly the same. Consequently, a further explanation for selfdisconnection is that consumers may suffer from limited attention/memory.

A reminder can be effective because time inconsistency, under this argument, is derived from a failure to forecast future expenditure leading to less consumption smoothing than would occur under perfect foresight (Karlan et al. 2010). A reminder/feedback implies voluntary and selective attention from the consumer given that they want to save for future energy consumption.

In the prepayment energy context, a reminder on consumption could be as follows: "Last year you spent $£ 20$ on gas between July and September and you spent $£ 120$ on gas between October and December". The reminder/feedback can be extended by introducing a saving cue, e.g. "By saving extra $£ 50$ during the summer time, you can smooth your gas expenses throughout the year". The reminder could be sent by e-mail or mobile SMS during period 0 . Interestingly, if the consumer does not wish to consume more energy during the winter, then self-rationing is not driven by reasons of dynamic inconsistency or by limited attention issues. The consumers who choose rationally to self-ration are those that we do not need to target since their benefits from self-rationing and self-disconnecting are greater than their costs. We want to target those customers whose costs exceed benefits because they are the ones who will benefit from a commitment contract.

\section{Data}

The data source used for examining the mechanism is from a survey developed in collaboration with British Gas designed specifically for prepayment gas customers. The survey was available online between January and February 2013 and was sent via email to 20,000 customers ( $11 \%$ of surveys were undelivered). Surveys with a significant small 
number of responses were dropped from the database. In total and for estimation purposes, we obtained 1541 usable responses.

The survey, designed to be representative of the prepayment consumers and fielded accordingly, included a series of detailed questions about the respondent's saving plan choice and demographics (age, gender, education, household size, and income). A wide range of questions to assess self-disconnection, saving behaviour, topping-up behaviour, opinions about the prepayment meter $^{3}$, and questions to measure self-control were also included. For a summary of the main variables employed in the paper see appendix, Table A1.

Regarding the questions on the preferences about the saving plan, we did not ask open-ended questions (e.g. "Do you want to make more spread and similar payments throughout the year?"). Instead, we gave a specific text for each of the saving plans, similar to the contracts' description in section 2.1 and asked the respondents which of the plans they would prefer (see Appendix for the questions related to the saving plan choice). This type of questions is usually referred to as "stated preference questions", and will allow us to use the "stated preference" questionnaire techniques described in Louviere et al. (2000). Nevertheless, these questions may involve some limitations: respondents may find some trade-offs difficult to evaluate because they are unfamiliar with the suggested saving plans; and once the number of attributes increases, the complexity and the number of comparisons increase, which may lead to a loss of interest from the respondent. For these reasons we took great care in explaining the different plans in detail and focus on differences in attribute levels. The attribute levels (i.e. level of flexibility and saving target) for the commitment contracts are presented in Table 1. The reminder/feedback has the following attribute levels: high level of flexibility and no saving target. We included in the survey one extra alternative ("none of the options") that we use as our main reference choice, which is valid as a constant for all respondents given that they were all using the same payment method at the moment of the survey and acts as a status quo alternative. The absence of a status quo alternative would bias interest in saving options upwards.

Socio-Economic Variables. Table 2 compares the age and gender of the respondents of the survey with the group of customers who have a contract with British Gas for the supply of gas through a prepayment meter. Our sample is representative with small differences in the

\footnotetext{
${ }^{3}$ Although, we have asked questions to assess their opinions over prepayment meter, we did not use them for the empirical analysis.

${ }^{4}$ Or using a more recent terminology "discrete choice experiments" questions (Carson and Louviere, 2011),
} 
number of customers aged between 22 and 34 years old and between 45 and 54 years old.

Table 2: Survey sample: control variables

\begin{tabular}{llrr}
\hline \hline Category & $\begin{array}{r}\text { Survey sample } \\
\text { (\%) }\end{array}$ & $\begin{array}{r}\text { PPM Gas in British Gas } \\
\text { (\%) }\end{array}$ \\
\hline Gender & Male & 37.8 & 39.4 \\
& Female & 62.2 & 59.4 \\
\hline Age & 21 and Under & 0.2 & 2.2 \\
& 22 to 34 & 5.6 & 25.9 \\
& 35 to 44 & 20.7 & 24.4 \\
& 45 to 54 & 38.5 & 24.7 \\
& 55 to 64 & 25 & 13.8 \\
& 65 and Over & 9.9 & 9.1 \\
\hline \hline
\end{tabular}

Table 3 shows the means and standard deviations of the explanatory variables. The consumers in the sample are, on average, between 45 and 54 years old, with basic and medium levels of education (around 31\% and 34\% respectively) and lower and medium levels of household income (approximately 33\% and 33\% respectively). The household is composed, on average, of two adults and one child. All variables are categorical except for the members of adults and children in the household. Information about household income and education are captured by a group of dichotomous variables, where the reference variables for each group are low income and no education. We now turn to a discussion of the main variables of interest.

Table 3: Descriptive statistics: demographic characteristics

\begin{tabular}{lccccccc}
\hline \hline Measures & \multicolumn{2}{c}{ Total } & \multicolumn{2}{c}{ Male } & \multicolumn{2}{c}{ Female } \\
\hline Income levels & & & & & & \\
Low income (up to £1000) & .414 & $(.493)$ & .405 & $(.491)$ & .419 & $(.494)$ \\
Medium income (£1001 to £2000) & .406 & $(.491)$ & .393 & $(.489)$ & .415 & $(.493)$ \\
High income (over £2000) & .166 & $(.373)$ & .187 & $(.391)$ & .153 & $(.361)$ \\
Education levels & & & & & & & \\
None & .133 & $(.340)$ & .158 & $(.365)$ & .119 & $(.323)$ \\
Basic (O-levels) & .346 & $(.476)$ & .280 & $(.449)$ & .386 & $(.487)$ \\
Medium (A-levels + Technical education) & .377 & $(.485)$ & .406 & $(.491)$ & .360 & $(.480)$ \\
Higher (Undergraduate + Postgraduate & .166 & $(.373)$ & .156 & $(.363)$ & .136 & $(.343)$ \\
degrees) & & & & & & & \\
\#Adults in the household & 2.19 & $(1.05)$ & 2.14 & $(1.08)$ & 2.21 & $(1.04)$ \\
\#Children in the household & .924 & $(1.11)$ & .636 & $(.989)$ & 1.07 & $(1.14)$ \\
\hline Observations & \multicolumn{2}{c}{1541} & & 583 & & 958 \\
\hline \hline
\end{tabular}

Notes: Standard deviations in parenthesis. Monthly household income includes any benefits. Low income and no education will be used as benchmark categorical variables. 
Self-disconnection and Emergency Credit. Table 4 shows our measures of selfdisconnection and emergency credit. At least $62 \%$ of the sample stated that had already used the emergency credit and around $37 \%$ had already self-disconnected at some point.

Table 4. Distribution of emergency credit and self-disconnection

\begin{tabular}{|c|c|c|c|}
\hline Answer & Freq. & Percent. & Cum. \\
\hline \multicolumn{4}{|c|}{ 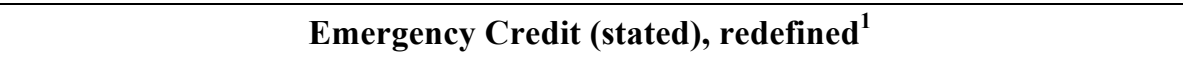 } \\
\hline \multicolumn{4}{|c|}{$\begin{array}{l}\text { To what extent do you agree with the following statement: I rarely use the } \\
\text { emergency credit. }\end{array}$} \\
\hline (0) Strongly agree, agree & 550 & 38.38 & 38.38 \\
\hline $\begin{array}{l}\text { (1) Strongly disagree, disagree, } \\
\text { neither agree nor disagree }\end{array}$ & 883 & 61.62 & 100 \\
\hline Total & 1,433 & 100 & \\
\hline \multicolumn{4}{|c|}{ Self-disconnection (stated), redefined } \\
\hline \multicolumn{4}{|c|}{$\begin{array}{l}\text { To what extent do you agree with the following statement: Sometimes the } \\
\text { emergency credit runs out. }\end{array}$} \\
\hline $\begin{array}{l}\text { (0) Strongly disagree, disagree } \\
\text { (1) Strongly agree, agree, neither }\end{array}$ & 828 & 60.61 & 60.61 \\
\hline agree nor disagree & 538 & 36.77 & 100 \\
\hline Total & 1,366 & 100 & \\
\hline
\end{tabular}

Inconvenience of Top-up. A possible explanation for a household using the emergency credit or self-disconnecting is that it is inconvenient to top-up, for example due to transaction costs. Every time consumers need to top-up, they have to go to an outlet or if the payment can be made through an online account, the consumers still need to have access to internet. Other reasons may include liquidity constraints or lack of income. In order to take into account this factor we have asked the respondents to answer, on a scale from "strongly disagree" to "strongly agree" including a "don't know" option, the sentence "Pay As You Go makes it easy to pay for my gas". From this we constructed the binary variable inconvenience of top up that is zero if the customer had answered "strongly agree" or "agree" to the question or one otherwise. In all redefined variables throughout the analysis, the "don't know" option was dropped. Interestingly, the majority of the respondents have stated that a prepayment meter does make it easy to pay for gas (see Table A2 for a cross-tabulation with selfdisconnection). 
Topping Up Behaviour. The consumers were asked to state whether they top up more over the winter or roughly the same over the year. This is summarized in the variable top up all year that equals to one if consumer $i$ tops up roughly the same all year around and zero if consumer $i$ tops up much more over the winter. The majority of the consumers choose to top up according to their needs, and so their top-ups were more frequent over the winter. From the consumers who top up roughly the same all year round, only $29 \%$ had self-disconnected; whereas $40 \%$ of those who top up more during the winter had already self-disconnected (see Table A3 in the Appendix). Although consumers who self impose a personal rule or internal commitment mechanism, such as topping up the same every week, are less exposed to selfdisconnection, there are still consumers that top up regularly and self-disconnect. This suggests that current regular top-up behaviour is not sufficient in preventing selfdisconnection.

Saving Behaviour. Consumers may have not been using the meter as a commitment device via regular top-ups, but still saved for the increase in energy spending. One question asked, on a scale from "strongly disagree" to "strongly agree", was "When I'm using less gas in warmer months I like to add any spare cash to my savings". 24\% of the consumers that answered this question, answered "strongly agree" or "agree" against $76 \%$ who answered "strongly disagree" or "disagree" or "neither agree nor disagree". This is a redefined variable: saving behaviour equals one if the customer answered "strongly agree" or "agree" and zero otherwise. Moreover, the relationship between saving behaviour and self-disconnection is not statistically significant (see Table A4). This suggests that consumers use the accumulated savings during the summer for expenses other than energy.

Spare Cash. Self-disconnection is associated with poverty. Following Bryan et al. (2010), behavioural anomalies significantly affect consumers with less disposable income. At this point, a relevant question is: do low-income consumers who self-disconnect have the opportunity to accumulate savings during the summer? When answering the question "I have spare cash in warmer months as I don't have to spend so much on gas", $20 \%$ of the consumers who have answered "strongly agree" or "agree" are in the low-income category (see Table A5). Eight percent out of those $20 \%$ had already self-disconnected. Consequently, a proportion of low-income consumers affected by self-disconnection also had opportunities to use a commitment contract. Banerjee and Mullainathan (2010) argue that low-income people consume relatively more temptation goods. Temptation and self-control problems 
affect both the rich and the poor though they influence and/or matter more for the poor. Therefore, through the decrease of temptation and increase in self-control, one may induce greater savings.

Self-control. We constructed a measure to assess the level of goal achievement of the individuals as a proxy for self-control. Psychologists have considered the impact of conscientiousness on self-control and goal achievement can be seen as one facet of conscientious trait (see the literature on the Big Five personality traits, e.g. Costa and Widiger 1994). We decided to focus on goal achievement since it is the most relevant facet of conscientious trait in explaining self-control in the context of self-disconnection. Due to the limit number of questions in the survey, we have a single question to assess goal achievement and thus, our question does not assess completely goal achievement but rather focuses on goal task, planning and procrastination issues.

Which of the following statements best describe you? (Choose two responses at most.)

(a) I usually achieve my goals.

(b) I usually avoid or delay a task that requires a lot of thinking.

(c) I have difficulties in completing a task that requires organization.

(d) I usually set-up weekly or monthly goals that I wish to achieve.

(e) I don't usually achieve my goals.

In order to construct an index for "goal achievement" from this question, we delineated three different levels: high, medium, and low goal achievement (see Table A6 in the Appendix for a better understanding of these variables). Individuals who usually achieve their goals (answered point a) have a high level of goal achievement. In contrast, individuals who usually do not achieve their goals (e) are seen as having a low level of goal achievement. The intermediate concept targets those individuals who have difficulties in achieving their goals (b, c and d). The majority of the respondents, 63\%, answered one option only. However, respondents could select two options, and so we need to define a rule to divide the answers between the three subsets (high, medium and low). Those that have answered options (a) and (d) are considered as high because (d) is stronger in terms of goal achievement than (b) or (c), whereas those that have answered (a) and (b) or (a) and (c) are considered as medium. These answers represent so far $90 \%$ of the total answers for this question. The remaining answers that have included (e) are considered as low type. Overall, the majority of the respondents (around 60\%) are considered as high goal achievement types 
against $10 \%$ of the sample that were considered as low goal achievement and $30 \%$ as medium goal achievement.

This index has a major limitation for firms and/or decision makers since information on attitudes, personality traits and/or behaviour is generally not available. In order to better understand how the information on goal achievement correlates with other easily observable variables, we conducted a correlation analysis (see Table 5).

Table 5. Correlations between variables characterizing individual heterogeneity

\begin{tabular}{|c|c|c|c|c|c|c|c|c|c|c|c|c|}
\hline & 1 & 2 & 3 & 4 & 5 & 6 & 7 & 8 & 9 & 10 & 11 & 12 \\
\hline 1. Household size & 1 & & & & & & & & & & & \\
\hline 2. Female & $.12 * * *$ & 1 & & & & & & & & & & \\
\hline 3. Low income & $-.29 * * *$ & .01 & 1 & & & & & & & & & \\
\hline 4. Medium income & $.16^{* * *}$ & .02 & $-.71 * * *$ & 1 & & & & & & & & \\
\hline 5. High income & $.16^{* * *}$ & -.04 & $-.38 * * *$ & $-.37 * * *$ & 1 & & & & & & & \\
\hline 6. Basic education & $.07 *$ & $.11 * * *$ & .00 & -.02 & .03 & 1 & & & & & & \\
\hline 7. Medium educ. & -.06 & $-.05^{*}$ & -.04 & $.07 * *$ & -.03 & $-.57 * * *$ & 1 & & & & & \\
\hline 8. High education & .03 & -.03 & $-.09 * * *$ & .02 & $.09 * * *$ & $-.30 * * *$ & $-.32 * * *$ & 1 & & & & \\
\hline 9. Low GA & -.06 & -.04 & .03 & -.02 & -.03 & .02 & -.01 & $-.06 * *$ & 1 & & & \\
\hline 10. Medium GA & -.06 & $.12 * * *$ & $.06^{*}$ & -.02 & -.04 & .04 & -.03 & -.01 & $-.22 * * *$ & 1 & & \\
\hline 11. High GA & $.09^{* *}$ & $-.09 * * *$ & $-.07 * *$ & .03 & $.06^{*}$ & $-.05 *$ & .04 & .04 & $-.41 * * *$ & $-.80 * * *$ & 1 & \\
\hline 12. Self-disc. & $.10 * * *$ & .03 & -.00 & .02 & -.03 & .01 & .03 & -.02 & .01 & $.12 * * *$ & $-.12 * * *$ & 1 \\
\hline
\end{tabular}

Notes: $* * *, * *, *$ stand for 1,5 , and 10 percent significant levels, respectively; GA stands for goal achievement.

Interestingly, education is related only to the extremes with the other variables. There is a negative correlation between basic education and high goal achievement and a negative correlation between high education and low goal achievement. Additionally, high goal achievement is significant negatively correlated with low income and female. The former result deserves special attention because those consumers that have low goal achievement levels and are low-income are precisely those consumers that can take advantage of a commitment contract. The latter correlation is more ambiguous since it might be explained either because female respondents in our sample have lower levels of goal achievement when compared to male respondents or because female reported goal achievement in a less confident manner. Nevertheless, the magnitude of correlation is quite small, around $9 \%$.

Further, we find that self-disconnection is significant negatively correlated with a high goal achievement. This is relevant in light of the discussion above that self-disconnection is affected by cognitive biases. In fact, this finding seems to clearly identify those consumers who do not need a commitment contract or a reminder, thus our non-target group of 
consumers. We also find a positive and statistically significant relationship between selfdisconnection and medium goal achievement. Given this positive correlation, it cannot be said that these consumers are truly consistent and one can say that there is a sign that these consumers lack self-control. But the question is, will these consumers accept a commitment contract? Are they sophisticated enough to be aware of their lack of self-control? We have introduced a question in the survey that we will use to inspect this point in the next section: "To what extent do you agree with the following statement, on a scale from strongly disagree to strongly agree: I get worried about running out of credit”. In fact, $52 \%$ of those that have answered "strongly agree" or "agree" in this question and have been considered as medium goal achievement, have already self-disconnected.

A further relevant question is: assuming that those respondents with medium goal achievement levels are a good proxy for those consumers that would accept a commitment contract, how could a firm identify them without the availability of information on selfcontrol? Table A7 in the Appendix shows the mean characteristics of those respondents that were indexed as medium goal achievement. These respondents are more likely to be between 34 and 54 years old, to have low and medium levels of income, to have basic and medium education and top-up more during the winter.

Saving Plans. Table 6 shows the distribution of the choices that consumers made with regard to the commitment contracts that were introduced in the previous section and the reminder. Interestingly, when asked to choose between the different commitment contracts, the reminder or none, $36 \%$ of the consumers have chosen the regular payments throughout the year, followed by almost $15 \%$ choosing the reminder option whereas the voluntary savings received least interest.

Table 6. Distribution of the different plans

\begin{tabular}{lrrr}
\hline \hline \multicolumn{1}{c}{ Preferred saving plan } & Freq. & Percent & Cum. \\
\hline Regular payments & 457 & 36.44 & 36.44 \\
Voluntary savings & 106 & 8.45 & 44.9 \\
Ad-hoc payments & 131 & 10.45 & 55.34 \\
Summer fixed payments & 47 & 3.75 & 59.09 \\
Reminder & 187 & 14.91 & 74 \\
None of the above & 326 & 26 & 100 \\
\hline Total & 1,254 & 100 & \\
\hline \hline
\end{tabular}




\section{Estimation Strategy}

First, our survey is designed to identify the type of consumers that would accept a commitment contract and/or a reminder. In order to increase consumer surplus, we need to target those consumers who actually need a commitment contract because, even though their costs of self-disconnection exceed the benefits, self-control issues constrain their ability to make a strictly rational choice predisposing them to relatively costly self-disconnection. For that purpose, we need to understand what are the determinants of self-disconnection. Second, we wish to know whether our proposed commitment contracts would be accepted by energy consumers and, if so, which contract they would prefer.

Testing for self-control problems in self-disconnection and in emergency credit. We analyse the determinants of stated self-disconnection, $S D_{i}$, and stated emergency credit, $E C_{i}$, through a probit estimation of the following equations:

$$
\begin{aligned}
S D_{i} & =\alpha_{0}+\boldsymbol{\alpha}_{1} \boldsymbol{x}_{1 i}+\boldsymbol{\alpha}_{2} \boldsymbol{x}_{2 i}+\alpha_{3} G A l_{i}+\alpha_{4} G A m_{i}+\eta_{i} \\
E C_{i} & =\gamma_{0}+\gamma_{1} \boldsymbol{x}_{1 i}+\gamma_{2} \boldsymbol{x}_{2 i}+\gamma_{3} G A l_{i}+\gamma_{4} G A m_{i}+\zeta_{i}
\end{aligned}
$$

where $\boldsymbol{x}_{1 i}$ represents a vector of demographic and economic characteristics and $\boldsymbol{x}_{2 i}$ represents a vector of variables that may help explaining self-disconnection. In the latter vector, we have included top up all year, saving behaviour, and inconvenience of top up. To measure self-control, we use our levels of goal achievement as dummy variables and use high goal achievement as a reference category in our estimations: $G A l_{i}=1$ if low goal achievement and zero otherwise; $G A m_{i}=1$ if medium goal achievement and zero otherwise; and $G A h_{i}=1$ if high goal achievement and zero otherwise.

Can we identify "sophisticated" and/or "naïve" consumers? A possible indication of this identification of types is to see whether consumers that have a low and/or medium levels of goal achievement are more likely to worry about running out of gas than the consumers with high goal achievement. A consumer can be worried about running out of credit for several reasons, but an interesting one is that they may already self-ration or even self-disconnect, and they are aware of their self-control issues. Thus, we expect that a "sophisticated" consumer is more likely to be worried about running out of gas, whereas the "naïve" is 
overconfident. We can use the dummy variable worried, that equals one if consumer $i$ has "agreed" or "strongly agreed" with the statement "I get worried about running out of credit", and zero otherwise. We use this dummy as a binary dependent variable in the following equation.

$$
\text { Worried }_{i}=\beta_{0}+\boldsymbol{\beta}_{1} \boldsymbol{x}_{1 i}+\beta_{2} G A l_{i}+\beta_{3} G A m_{i}+\varepsilon_{i}
$$

In order to test this hypothesis, we estimated a probit model where worried is the dependent variable; as explanatory variables we included a vector of demographic, including gender and economic variables, and a measure of self-control. $\varepsilon_{i}$ is a stochastic disturbance.

Preferred Saving Plan. In the second step of our analysis we show a theoretical framework for consumers choosing a certain commitment device. A consumer $i$ is faced with a choice between the following alternatives or plans: (1) regular payments throughout year, (2) voluntary savings target, (3) ad-hoc extra payments, (4) summer fixed extra payments, (5) reminder, (6) none of the options.

Following the additive random utility model for multiple alternatives (see Cameron and Trivedi 2005), the individual utility associated with the $j^{\text {th }}$ choice can be represented as

$$
U_{i j}=\boldsymbol{x}_{\boldsymbol{i}} \boldsymbol{\beta}_{j}+\varepsilon_{i j}, \quad j=1, \ldots, 6
$$

where $U_{i j}$ represents the utility of consumer $i$ of a plan $j . \varepsilon_{i j}$ is the random component of utility that stands for the consumers unobserved characteristics. $\boldsymbol{\beta}_{j}$ are the parameters of the model.

Each consumer decision is based on choosing the plan that offers the highest utility level. A certain consumer $i$ chooses plan $j$ if the utility derived from it is higher than the utility that he had derived from choosing "none of the options" and from all other plans, $U_{i j} \geq U_{i s}$, for all $j \neq s$. The choice $s$, "none of the options", is used as the reference choice. Then, the probability for customer $i$ to choose plan $j$ is given by 


$$
\begin{aligned}
& \operatorname{Pr}\left(\text { Preferred Plan }{ }_{i}=j\right)=\operatorname{Pr}\left(U_{i j} \geq U_{i s}, \forall j \neq s\right)= \\
& \quad=\operatorname{Pr}\left(\boldsymbol{x}_{i} \boldsymbol{\beta}_{j}+\varepsilon_{i j} \geq \boldsymbol{x}_{i} \boldsymbol{\beta}_{s}+\varepsilon_{i s}, \forall j \neq s\right)= \\
& \quad=\operatorname{Pr}\left(\boldsymbol{x}_{i} \boldsymbol{\beta}_{j}-\boldsymbol{x}_{i} \boldsymbol{\beta}_{s} \geq \varepsilon_{i s}-\varepsilon_{i j}, \forall j \neq s\right)
\end{aligned}
$$

We assume that the errors $\varepsilon_{i j}$ are iid type 1 extreme value, with density $f\left(\varepsilon_{i j}\right)=$ $e^{-\varepsilon_{i j}} \exp \left(-e^{-\varepsilon_{i j}}\right), j=1, \ldots, 6$. This results in the multinomial logit Pr(Preferred Plan $_{i}=$ $j)=\frac{e^{x_{i} \beta_{j}}}{\sum_{s=1}^{6} e^{x_{i} \beta_{s}}}$. The model then takes the following form:

$$
\begin{aligned}
P_{i j}= & \operatorname{Pr}\left(\text { Preferred } \text { Plan }_{i}=j\right) \\
& =F\left(\beta_{0 j}+\boldsymbol{\beta}_{1 j} \boldsymbol{x}_{1 i}+\boldsymbol{\beta}_{2 j} \boldsymbol{x}_{2 i}+\beta_{3 j} S D_{i}+\beta_{3 j} G A l_{i}+\beta_{4 j} G A m_{i}+\varepsilon_{i j}\right)
\end{aligned}
$$

where Preferred Plan $_{i}$ represents a customer decision about plan $j$. As before, $\boldsymbol{x}_{1 i}$ represents a vector of demographic and economic characteristics and $\boldsymbol{x}_{2 i}$ includes inconvenience of top up and saving behaviour. This is estimated using a multinomial logit. By estimating equation (6) using a multinomial logit model, we examine the direct impact of self-disconnection, goal achievement, inconvenience of top up, saving behaviour and individual socioeconomic characteristics on the probability of choosing between one of the commitment contracts, or the reminder against the reference category of not choosing any of the listed options.

\section{Results}

\subsection{Self-disconnection and Emergency Credit}

Estimation results for emergency credit and self-disconnection are obtained by estimating equations (1) and (2). Table 7 reports the average marginal effects for these equations controlling for self-control (models IV and II) and without controlling for self-control (models III and I).

Although income is significant in the emergency credit models, i.e. a lower income level increases the probability of using emergency credit; the same does not applied in the self-disconnection model. Education does not seem to affect the use of emergency credit or the tendency to self-disconnect. The inconvenience of top-up increases the predicted 
probability to self-disconnect by around $17 \%$ holding all other variables at their means (model III); whereas top up all year decreases the predicted probability of using the emergency credit and of self-disconnection by around $16 \%^{5}$ (model I). A regular top up seems to be effective in reducing self-disconnection, however, as discussed in the previous sections, it does not completely offset it. Saving behaviour (i.e. being more prone to save) affects significantly and negatively the use of emergency credit but is not significantly associated with self-disconnection. This emphasizes the finding in the previous section that self-imposing a commitment mechanism such as saving during warmer months is not sufficient in minimizing self-disconnection.

Result 1. A self-commitment device such as saving during warmer months is not sufficient in minimizing self-disconnection.

\footnotetext{
${ }^{5}$ Notice that these are categorical variables and so the average marginal effects show how the probability of stated selfdisconnection and stated emergency credit change as the categorical variable, e.g. inconvenience of top-up, changes from 0 to 1 , holding all other variables at their means.
} 
Table 7. Probit estimation for emergency credit and for self-disconnection

\begin{tabular}{|c|c|c|c|c|}
\hline \multirow[t]{2}{*}{$\begin{array}{c}\text { Average Marginal } \\
\text { Effects, Probit }\end{array}$} & \multicolumn{2}{|c|}{ Dep. Var.: Emergency credit } & \multicolumn{2}{|c|}{$\begin{array}{c}\text { Dep. Var.: } \\
\text { Self-disconnection }\end{array}$} \\
\hline & I & II & III & IV \\
\hline Age & & & & \\
\hline 35 to 44 & $\begin{array}{l}.038 \\
(.222)\end{array}$ & $\begin{array}{l}.043 \\
(.230)\end{array}$ & $\begin{array}{l}-.114 \\
(.225)\end{array}$ & $\begin{array}{l}-.078 \\
(.229)\end{array}$ \\
\hline 45 to 54 & $\begin{array}{l}-.017 \\
(.211)\end{array}$ & $\begin{array}{l}-.000 \\
(.219)\end{array}$ & $\begin{array}{l}-.093 \\
(.216)\end{array}$ & $\begin{array}{l}-.070 \\
(.220)\end{array}$ \\
\hline 55 to 64 & $\begin{array}{l}-.007 \\
(.220)\end{array}$ & $\begin{array}{l}-.054 \\
(.229)\end{array}$ & $\begin{array}{l}-.107 \\
(.224)\end{array}$ & $\begin{array}{l}-.063 \\
(.229)\end{array}$ \\
\hline Over 65 & $\begin{array}{l}-.152 \\
(.253)\end{array}$ & $\begin{array}{l}-.122 \\
(.262)\end{array}$ & $\begin{array}{l}-.206^{* *} \\
(.266)\end{array}$ & $\begin{array}{l}-.155 \\
(.274)\end{array}$ \\
\hline Female & $\begin{array}{l}-.038 \\
(.094)\end{array}$ & $\begin{array}{l}-.021 \\
(.099)\end{array}$ & $\begin{array}{l}.002 \\
(.096)\end{array}$ & $\begin{array}{l}.009 \\
(.101)\end{array}$ \\
\hline Education & & & & \\
\hline Medium & $\begin{array}{l}.042 \\
(.096)\end{array}$ & $\begin{array}{l}.050 \\
(.100)\end{array}$ & $\begin{array}{l}.016 \\
(.097)\end{array}$ & $\begin{array}{l}.025 \\
(.101)\end{array}$ \\
\hline Higher & $\begin{array}{l}.014 \\
(.133)\end{array}$ & $\begin{array}{l}.002 \\
(.136)\end{array}$ & $\begin{array}{l}.018 \\
(.136)\end{array}$ & $\begin{array}{l}.017 \\
(.140)\end{array}$ \\
\hline Income & & & & \\
\hline Medium & $\begin{array}{l}.105 * * * \\
(.098)\end{array}$ & $\begin{array}{l}.131 * * * \\
(.102)\end{array}$ & $\begin{array}{l}-.007 \\
(.099)\end{array}$ & $\begin{array}{l}-.001 \\
(.103)\end{array}$ \\
\hline High & $\begin{array}{r}.041 \\
(.129)\end{array}$ & $\begin{array}{l}.078 \\
(.135)\end{array}$ & $\begin{array}{l}-.043 \\
(.131)\end{array}$ & $\begin{array}{l}-.034 \\
(.137)\end{array}$ \\
\hline Household adults & $\begin{array}{r}.033 * * \\
(.043)\end{array}$ & $\begin{array}{l}.030^{*} \\
(.045)\end{array}$ & $\begin{array}{c}.026 \\
(.043)\end{array}$ & $\begin{array}{l}.028 \\
(.045)\end{array}$ \\
\hline Saving behavior & $\begin{array}{c}-.139 * * * \\
(.103)\end{array}$ & $\begin{array}{c}-.143 * * * \\
(.109)\end{array}$ & $\begin{array}{l}.018 \\
(.105)\end{array}$ & $\begin{array}{l}.012 \\
(.110)\end{array}$ \\
\hline Top up all year & $\begin{array}{c}-.160 * * * \\
(.149)\end{array}$ & $\begin{array}{c}-.183 * * * \\
(.155)\end{array}$ & $\begin{array}{c}-.159 * * * \\
(.158)\end{array}$ & $\begin{array}{c}-.166 * * * \\
(.164)\end{array}$ \\
\hline Inconvenience of top up & $\begin{array}{l}.036 \\
(.095)\end{array}$ & $\begin{array}{l}.030 \\
(.099)\end{array}$ & $\begin{array}{l}.171 * * * \\
(.095)\end{array}$ & $\begin{array}{l}.164 * * * \\
(.099)\end{array}$ \\
\hline Goal Achievement & & & & \\
\hline Low & & $\begin{array}{l}.062 \\
(.155)\end{array}$ & & $\begin{array}{l}.100^{*} \\
(.154)\end{array}$ \\
\hline Medium & & $\begin{array}{l}.053 \\
(.104)\end{array}$ & & $\begin{array}{l}.122 * * * \\
(.103)\end{array}$ \\
\hline Constant & $\begin{array}{l}.182^{\mathrm{a}} \\
(.244) \\
\end{array}$ & $\begin{array}{l}.057^{\mathrm{a}} \\
(.260) \\
\end{array}$ & $\begin{array}{l}-.248^{\mathrm{a}} \\
(.252)\end{array}$ & $\begin{array}{l}-.493^{\mathrm{a}} \\
(.265) \\
\end{array}$ \\
\hline Pseudo R-squared & .043 & .050 & .037 & .045 \\
\hline Number of observations & 895 & 840 & 857 & 805 \\
\hline Prob $>$ chi 2 & 0 & 0 & 0 & 0 \\
\hline
\end{tabular}

We also find a significant relationship between goal achievement and selfdisconnection. Note that we have used as a reference category the high level of goal achievement. Thus, moving from the high category to the medium one increases the predicted probability of self-disconnection by $12.2 \%$, holding all other variables at their means. This 
emphasizes our next result, that self-control, measured through goal achievement, plays a role in self-disconnection.

Result 2. Self-control plays a role in self-disconnection.

Regarding the emergency credit, neither of these variables is statistically significant nor the marginal effects are large. This is reasonable since the use of emergency credit is not closely related to self-control issues. A household can use the emergency credit because it simply forgot to top up, or it may even be the case that the emergency credit is being used as a short small "loan" since it involves no interest payment, and hence its use is rational.

Robustness Check. We tested the models using a different definition of the dependent variables. We dropped the "neither agree nor disagree" category from the variables selfdisconnection and emergency credit. No sign and/or statistically significant changes happened in terms of emergency credit, only in terms of the magnitude of the coefficients. Regarding the self-disconnection model, the sign and significance of the main explanatory variables did not suffer change, however the significance of the model was reduced, possibly due to the lower number of observations. The similarity between the models with the two different definitions suggests that our former definition is correct.

In the estimation of equations (1) and (2) we have assumed that the two dependent variables, self-disconnection and emergency credit, are independent and therefore we have estimated them separately. Since the respondents that self-disconnect have used the emergency credit, one can argue that both equations are related. If the error terms are correlated, then we can gain a more efficient estimator by estimating the two equations jointly. As a robustness check, we estimated a seemingly unrelated bivariate probit regression. Table A8 in the Appendix reports estimates of this model with the explanatory variables on goal achievement in the equation of self-disconnection but not in the equation of emergency credit, and the rest remaining the same. The results are similar to the results shown in Table 7, however, it turns out that the two equations are statistically significantly correlated but the magnitude of the estimates of the correlation error terms of the equations is not so large $(\mathrm{rho}=0.258)$. 


\subsection{Worried}

Table 8 shows the average marginal effects obtained through the probit estimation of equation (3). Interestingly, low goal achievement increases the predicted probability of becoming worried about running out of credit. Moving from the high category to the low one increases the predicted probability of being worried by $22.7 \%$, holding all other variables at their means. This shows signs of awareness among those consumers who feel that they might run out of gas. Those consumers who know that they will not self-disconnect have no reason to be worried and so represent those consumers that we do not want to target with a commitment contract, or even a reminder. Nevertheless, this analysis is not sufficient to clearly identify "sophisticated" consumers and "naïve" consumers in our sample especially because "naïve" consumers tend to be overconfident and therefore, might have overstated their true level of goal achievement.

Table 8. Self-control variables on worried

\begin{tabular}{lc}
\hline \hline Average Marginal Effects, & Dep. Var.: Worried \\
Probit & $.101^{* * *}$ \\
\hline Female & $(.097)$ \\
& \\
Education & -.018 \\
Medium & $(.100)$ \\
& -.014 \\
Higher & $(.136)$ \\
& \\
Income & -.038 \\
Medium & $(.102)$ \\
& -.035 \\
High & $(.135)$ \\
& -.006 \\
Household adults & $(.045)$ \\
& $.227 * *$ \\
Goal Achievement & $(.178)$ \\
Low & $.077^{* *}$ \\
& $(.104)$ \\
Medium & $.268^{\text {a }} * *$ \\
Constant & $(.251)$ \\
\hline Pseudo R-squared & .04 \\
Number of observations & 878 \\
Prob $>$ chi2 & .00 \\
\hline \hline Notes: Average marginal effects are reported. Robust standard \\
errors are in parenthesis. $* * *, * *, *$ stand for 1,5, and 10 percent \\
significant levels. Percent correctly predicted: 70.05. Age under \\
goal achievement were used as reference categories. ${ }^{\text {a }}$ Coefficient \\
estimates. Age categorical variables are here omitted. \\
\\
\\
\end{tabular}




\subsection{Preferred Saving Plan}

Though a significant percentage (around 36\%) of consumers have chosen regular payments saving plan as their preferred option, as it is shown in Table 6, plenty of comments expressed some concern about the lack of flexibility. Thus, we will investigate deeper which type of customer chooses each plan.

Table 9 shows the estimation results for the choice of the preferred saving plan. All the saving plans are compared to the "none of the options" choice. We find that a higher age reduces the likelihood of choosing a saving plan (with the exception of the summer fixed payments plan, which is not statistically significant). Keeping all other variables at their means, the predicted probability of choosing a regular payment plan is $1.7 \%$ higher for those that had already self-disconnected and around 16\% higher for those who find PPMs of not make it easier to pay. This contrasts with ad-hoc payments since having self-disconnection decreases the predicted probability of choosing ad-hoc payments.

For both plans regular payment and reminder, a higher income leads to a greater likelihood of choosing a saving plan instead of none. These results also suggest a relationship between self-disconnection and saving plans, which leads to the following result.

Result 3. A household that stated that it had already self-disconnected has a higher probability of accepting a commitment device, especially for the contract with summer fixed payments. 
Table 9. Multinomial logit: preferred plan (base comparison: "None of the options")

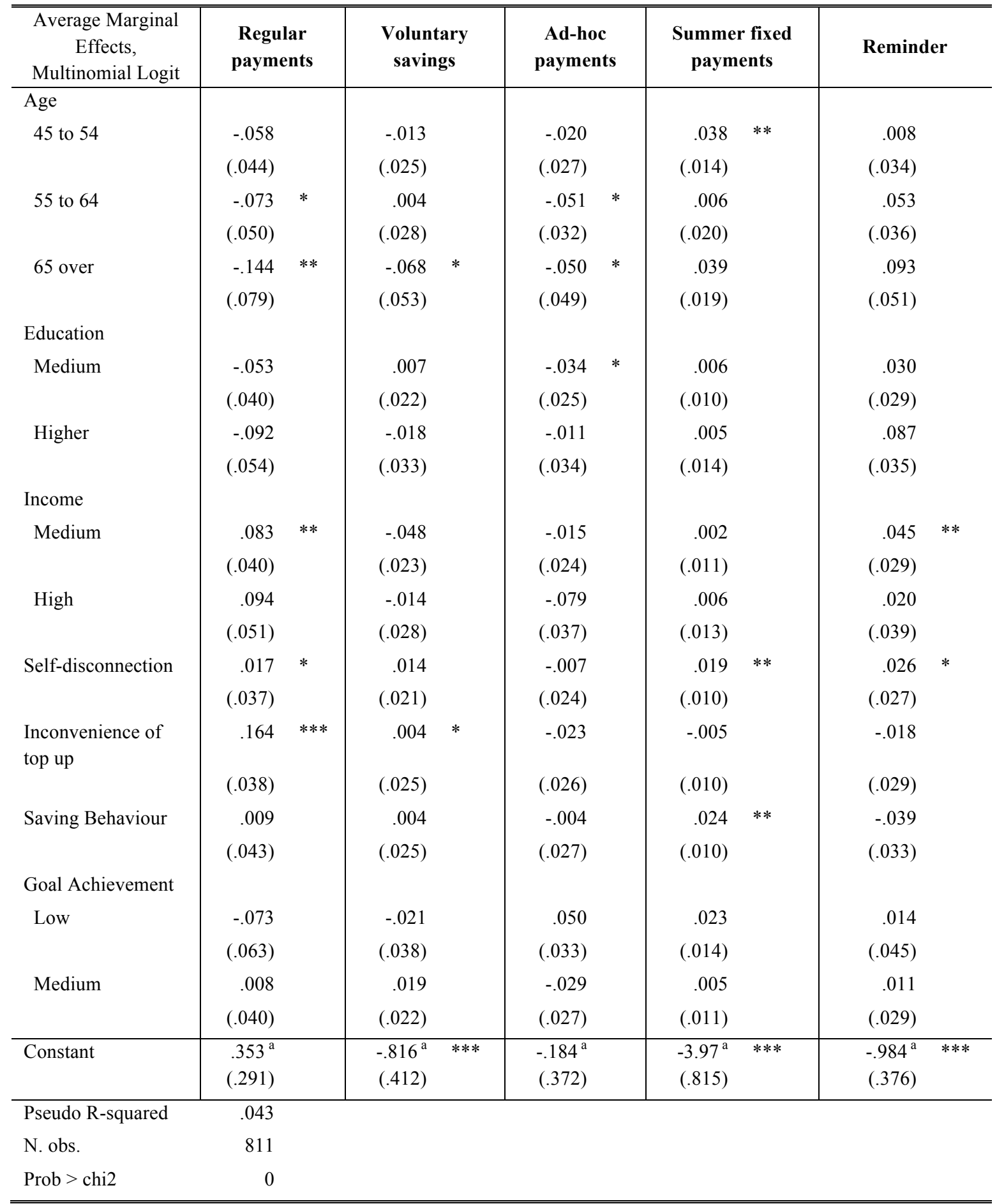

Notes: Average marginal effects are reported. Standard errors calculated by the Delta method are in parentheses. $* * *, * *$, * stand for 1,5, and 10 percent significant levels, respectively and the standard errors are in parenthesis. "None of the options" is the base outcome. Age under 22, Age to 34 and Age to 44, none and low education, low income and high goal achievement were used as reference categories. ${ }^{a}$ Coefficient estimates. Small-Hsiao test of independence irrelevant alternatives assumption (IIA) was computed and we cannot reject the null hypothesis of non-violation of IIA.

Overall, the above results demonstrate that there is scope to introduce a commitment contract. We show that an internal commitment/self-commitment device is not sufficient in eliminating self-disconnections. We find that a consumer/household who has already 
experienced self-disconnection has a greater probability of accepting a commitment contract. Although our multinomial logit model did not show a significant importance of our measure of self-control as a predictor of the different types of commitment contract and/or reminder, we find that self-control has a great importance in predicting self-disconnection.

\section{Discussion}

Both low-income households and households revealing that they have already suffered from self-disconnection deserve special attention. Tables 10 and 11 show the choices made by these two groups of households. For both groups, households prefer a regular payment throughout the year. Around 89 consumers who had self-disconnected preferred not to have a saving plan. One reason for this is that these consumers may be unaware of their self-control issues. In fact, 46\% (35 out of 89 ) of the respondents that answered "none of the options" have self-disconnected, but also have stated that they usually achieve their goals. This shows a certain sign of naiveté. The reminder could help these consumers to be more aware of potential self-control issues and/or likely increases in consumption during the winter.

The other explanation, which may explain it, is a failure to understand the saving plan. In fact, $40 \%$ (41 out 89 ) of the respondents that answered "none of the options" have self-disconnected and have no or low education levels. This shows us that there is a need to explain the different saving plans more clearly and to use less formal educated language so as to reach all consumers. A further explanation is that these 89 consumers may face extreme financial constraints and the complete lack of spare cash makes a saving plan not possible. In fact, $37 \%$ (33 out of 89 ) of the respondents that answered "none of the options" have selfdisconnected and have low income.

Table 10. Cross tabulation: preferred saving plan vs. low-income

\begin{tabular}{|c|c|c|c|c|c|c|c|c|}
\hline & \multicolumn{8}{|c|}{ Preferred saving plan } \\
\hline & & $\begin{array}{c}\text { Regular } \\
\text { payments }\end{array}$ & $\begin{array}{r}\text { Voluntary } \\
\text { savings }\end{array}$ & $\begin{array}{r}\text { Ad-hoc } \\
\text { payments }\end{array}$ & $\begin{array}{r}\text { Summer } \\
\text { fixed } \\
\text { payments }\end{array}$ & Reminder & None & Total \\
\hline \multirow{3}{*}{ Low income } & 0 & 252 & 43 & 59 & 26 & 96 & 127 & 603 \\
\hline & 1 & 142 & 44 & 51 & 14 & 53 & 115 & 419 \\
\hline & Total & 394 & 87 & 110 & 40 & 149 & 242 & 1,022 \\
\hline
\end{tabular}

Notes: Pearson chi2(5) $=15.2764(\mathrm{p}=.009)$. 
Table 11. Cross tabulation: preferred saving plan vs. self-disconnection

\begin{tabular}{|c|c|c|c|c|c|c|c|c|}
\hline & \multicolumn{8}{|c|}{ Preferred saving plan } \\
\hline & & $\begin{array}{c}\text { Regular } \\
\text { payments }\end{array}$ & $\begin{array}{r}\text { Voluntary } \\
\text { savings }\end{array}$ & $\begin{array}{r}\text { Ad-hoc } \\
\text { payments }\end{array}$ & $\begin{array}{r}\text { Summer } \\
\text { fixed } \\
\text { payments }\end{array}$ & Reminder & None & Total \\
\hline \multirow{3}{*}{$\begin{array}{c}\text { Self- } \\
\text { disconnection }\end{array}$} & 0 & 245 & 54 & 75 & 20 & 95 & 206 & 695 \\
\hline & 1 & 178 & 41 & 48 & 20 & 74 & 89 & 450 \\
\hline & Total & 423 & 95 & 123 & 40 & 169 & 295 & 1,145 \\
\hline
\end{tabular}

Notes: Pearson chi2(5) $=15.6226(\mathrm{p}=.008)$.

Overall, consumers are interested in a saving plan and in general they agree that it would be a good way to spread the cost of seasonal changes in gas use ${ }^{6}$. We find that those households stating they have already self-disconnected would like to commit to a saving plan. When asked specifically about their preferred plan, a significant percentage of the consumers have chosen the regular payments saving plan as their preferred option, although many respondents commented on the lack of flexibility ${ }^{7}$. Moreover, consumers understand that a commitment contract can help them to control their gas bills but do not fully understand the possibility of positive synergies in terms of avoiding temptations to spend on things that they do not need.

Based on our findings, we would propose a commitment contract that shares some of the characteristics of the regular payments, while allowing for a greater flexibility. For example, the customer can make extra payments when they prefer/can, but at the beginning of each summer the energy firm suggests an equal weekly/monthly amount (based on the previous year's consumption) that the customer can meet in order to smooth consumption through the year.

\section{Conclusion}

In this paper we designed different contracts to be offered by an energy firm that involve a commitment from the consumer. These contracts differ in terms of flexibility and saving target. We proposed also a reminder for consumers who do not wish to commit to a specific

\footnotetext{
${ }^{6}$ Customers were asked to answer in a scale from "strongly disagree" to "strongly agree" the following statements about their preferred saving plan: "It would be a good way to spread the cost of seasonal changes in gas use."; "It would help me focus on budgeting to cover my gas needs."; "It sounds too complicated."; "I'd worry about losing the credit I had saved."; and "It could help me reduce my spending on non-essential purchases.".

${ }^{7}$ In the survey, customers could leave any comments with regards to the saving plans. The customers showed some concerns regards to loss of flexibility, lack of spare cash, possible increases on the gas prices, loss of the interest during the summer, likelihood to forget to save, and also mistrust from the profit-maximizing firm.
} 
plan that involves savings, either because they do not think that they need it, although some of them might actually need it, or because they do not wish to commit to one firm. These interventions, under certain conditions, can lead to an increase in consumer surplus. Among these conditions are the correct identification of those consumers who need a commitment device and the "no introduction of extra switching costs" for the consumer of either changing tariff or firm. If overall firm costs also decrease as a result of our proposed mechanism then there are compelling reasons to believe that our mechanism can lead to an increase in social welfare. Nevertheless, a deeper welfare analysis would need to be undertaken before reaching such a conclusion. We plan to implement this in future research.

It is ambiguous whether an increase of the awareness of self-control issues can have an impact on other expenditures other than energy. Further, the empirical part of the study has a major limitation: we relied exclusively on a self-reported questionnaire. These limitations suggest that future research should experimentally test the effectiveness of a commitment contract and feedback/reminder to PPM gas consumers. A follow-up survey could then test whether there are any spillover effects of other types of expenditure.

Our analysis has implications for the policy debate on the role of the prepayment smart meter in the context of fuel poverty. This link to poverty emphasizes the importance of the present study in providing specific and simple solutions to increase levels of energy comfort. The solution proposed in this paper does not demand any costs to the government, and, is likely to increase social welfare. 


\section{References}

Ariely, D. and K. Wertenbroch (2002), "Procrastination, Deadlines, and Performance: SelfControl by Precommitment," Psychological Science, 13 (3): 219-24.

Ashraf, N., N. Gons, D. Karlan and W. Yin (2003), "A Review of Commitment Savings Products in Developing Countries," Asian Development Bank Economics and Research Department, Working Paper 45.

Ashraf, N., D. Karlan and W. Yin (2006), "Tying Odysseus to the Mast: Evidence from a Commitment Savings Product in the Philippines," Quarterly Journal of Economics, 121(2): 673-97.

Barnerjee, Abhijit V. and Sendhil Mullainathan (2010), "The Shape of Temptation: Implications for the Economic Lives of the Poor," NBER Working Papers No.15973.

Benartzi, Shlomo and Richard H. Thaler (2004), "Save More Tomorrow: Using Behavioral Economics to Increase Employee Savings," Journal of Political Economy, 112(1): S164-87.

Bernheim, B.D. and A. Rangel (2004), "Addiction and Cue-triggered Decision Processes," American Economic Review 94(5): 1558-90.

Beshears, J., J.J. Choi, D. Laibson, B.C. Madrian, and J. Sakong (2011), "Self Control and Liquidity: How to Design a Commitment Contract”. Working Paper.

Bryan G., Dean Karlan and Scott Nelson (2010), "Commitment Devices," Annual Review of Economics, 2: 671-98.

Brocas, I., J. D. Carrillo, M. Dewatripont (2004), “Commitment Devices under Self-control Problems: An Overview," in I. Brocas, J. D. Carrillo eds., The psychology of economic decisions: Reasons and choices, Vol. 2 Oxford University Press, Oxford, UK.

Brutscher, Philipp-Bastian (2012), "The Energy Use of Low-Income Households - A Behavioural Perspective," PhD Thesis, University of Cambridge.

Brutscher, Philipp-Bastian (2012a), "Making Sense of Oil Saving Schemes," Cambridge Working Paper in Economics 1203.

Brutscher, Philipp-Bastian (2012b), "Self-Disconnection among Pre-Payment Customers - A Behavioural Analysis," Cambridge Working Paper in Economics 1214.

Cameron, A.C., and P.K. Trivedi (2005), "Microeconometrics: Methods and Applications," Cambridge University Press, New York.

Carson, Richard T. and Jordan J. Louviere (2011), "A Common Nomenclature for Stated Preference Elicitation Approaches," Environmental and Resource Economics, 49(4): 539-59. 
Consumer Focus (2010), Pre-payment Meter Users and Selfdisconnection. http://www.consumerfocus.org.uk/assets/1/files/2010/02/Consultancyrecommendations-to-Consumer-Focus.pdf

Costa, Paul T., and Thomas A. Widiger (1994), Ed Personality Disorders and the Five Factor Model of Personality. Washington, DC: American Psychological Association.

Frederick, Shane, George Loewenstein and Ted O'Donoghue (2002), “Time Discounting and Time Preference: A Critical Review," Journal of Economic Literature, 40(2): 351401.

Fudenberg, Drew and David K. Levine (2006), "A Dual-Self Model of Impulse Control," American Economic Review, 96(5): 1449-76.

Gul, Faruk and Pesendorfer (2001), "Temptation and self-control," Econometrica, 69(6): 1403-35.

Laibson, David (1997), “Golden Eggs and Hyperbolic Discounting," Quarterly Journal of Economics, 112(2): 443-77.

Loewenstein, George (2000), "Emotions in Eeconomic Theory and Economic Behaviour," American Economic Review, 90(2): 426-32.

Louviere, Jordan J., David A. Hensher and Joffre D. Swait (2000), Stated choice methods: analysis and applications. Cambridge: Cambridge University Press.

Karlan, D., M. McConnell, S. Mullainathan and J. Zinman (2010), "Getting to the Top of the Mind: How Reminders Increase Saving,” NBER Working Papers No.16205.

O’Donoghue, T. and M. Rabin (1999), "Doing It Now or Later," American Economic Review, 89 (March): 103-24.

O’Donoghue, T. and M. Rabin (2001), “Choice and procrastination," The Quarterly Journal of Economics, 116: 121-60.

Ofgem (2012), Domestic Suppliers' Quarterly Social Obligations Data - Quarters 1 and 2 2012.

http://www.ofgem.gov.uk/Sustainability/SocAction/Monitoring/SoObMonitor/Docum ents1/Q1\%202012.pdf

O’Sullivan, K. C., P. L. Howden-Chapman, G. M. Fougere, S. Hales, and J. Stanley (2013), "Empowered? Examining Self-disconnection in a Postal Survey of Electricity Prepayment Meter Consumers in New Zealand," Energy Policy, 52: 277-87.

Strotz, Robert H (1956), "Myopia and Inconsistency in Dynamic Utility Maximization," Review of Economic Studies, 23: 165-80. 


\section{Appendix}

Table A1. List of main variables

\begin{tabular}{|c|c|}
\hline Variable & Detailed Description \\
\hline Age & Age of respondent. Categorical ordered variable. \\
\hline Female & Dummy for the gender of the respondent, Male if $=0$ and Female otherwise \\
\hline \#adults household & No. persons with more than 16 years old in the household. \\
\hline \#children household & No. children in the household with less or equal to 16 years old. \\
\hline Household size & No. people in the household \\
\hline Household income & Household monthly income, including any benefits. Categorical ordered variable \\
\hline Low & $\begin{array}{l}\text { Dummy variable }=1 \text { if household monthly income is up to } £ 1000 \text {, and }=0 \text {, } \\
\text { otherwise. }\end{array}$ \\
\hline Medium & $=1$ if household monthly income is $£ 1001$ to $£ 2000$, and $=0$, otherwise. \\
\hline High & $=1$ if household monthly income is over $£ 2000$, and $=0$, otherwise. \\
\hline Education & Education level of the respondent. \\
\hline None & $\begin{array}{l}=1 \text { if the highest education that the respondent obtained is lower than basic, and } \\
=0, \text { otherwise. }\end{array}$ \\
\hline Basic (O-levels) & $=1$ if the highest degree is basic education, and $=0$, otherwise. \\
\hline $\begin{array}{l}\text { Medium (A-levels and } \\
\text { vocational/professional education) }\end{array}$ & $=1$ if the highest degree is medium education, and $=0$, otherwise. \\
\hline $\begin{array}{l}\text { Higher (Univeristy degree and } \\
\text { postgraduate) }\end{array}$ & $=1$ if the highest degree is higher education, and $=0$, otherwise. \\
\hline Emergency credit (stated) & $\begin{array}{l}\text { To what extent do you agree with the statement: I rarely use the emergency } \\
\text { credit. Strongly disagree }=1,=2,=3,=4 \text {, Strongly agree }=5 \text {. Redefined into } \\
\text { dummy variable. }=1 \text { if }\end{array}$ \\
\hline Self-disconnection (stated) & $\begin{array}{l}\text { To what extent do you agree with the statement: Sometimes the emergency credit } \\
\text { runs out. Strongly disagree }=1,=2,=3,=4 \text {, Strongly agree }=5 \text {. Redefined into } \\
\text { dummy variable. }=1 \text { if }\end{array}$ \\
\hline Top up all year & $\begin{array}{l}\text { Which of the statements is most applicable to your spend on gas throughout the } \\
\text { year? = } 0 \text { if answered I top up much more on my gas meter over the winter than } \\
\text { over the summer, =1 if answered I top up roughly the same all year around. }\end{array}$ \\
\hline Saving behaviour & $\begin{array}{l}\text { Thinking about your lifestyle and your gas usage, to what extent do you agree } \\
\text { with: When I'm using less gas in warmer months I like to add any spare cash to } \\
\text { my savings. Strongly disagree }=1,=2,=3,=4, \text { Strongly agree }=5 \text {. Redefined into } \\
\text { dummy variable. }=1 \text { if Saving behavior }=5 \text { or }=4 \text {, and }=0 \text {, otherwise. }\end{array}$ \\
\hline Inconvenience of top up & $\begin{array}{l}\text { To what extent do you agree with the statement regarding the overall opinion } \\
\text { about the saving plan: Pay As You Go makes it easy to pay for my gas. Strongly } \\
\text { disagree }=1,=2,=3,=4 \text {, Strongly agree }=5 \text {. Redefined into dummy variable. }=1 \text { if } \\
\text { Inconvenience of top up }=1 \text { or }=2 \text { or }=3 \text {, and }=0 \text { otherwise. }\end{array}$ \\
\hline Preferred Plan (PP) & $\begin{array}{l}\text { Binary Variable. Regular payment throughout the year }=1 \text {, Voluntary savings } \\
\text { target }=2 \text {, Ad-hoc extra payments }=3 \text {, Summer fixed extra payments }=4 \text {, Reminder } \\
\text { on consumption }=5\end{array}$ \\
\hline Worried & $\begin{array}{l}\text { To what extent do you agree with the statement regarding the overall opinion } \\
\text { about the saving plan: I'd worry about losing the credit I had saved. Strongly } \\
\text { disagree }=1,=2,=3,=4 \text {, Strongly agree }=5 \text {. Redefined into dummy variable. }=1 \text { if } \\
\text { Worried }=5 \text { or }=4 \text {, and }=0 \text { otherwise. }\end{array}$ \\
\hline
\end{tabular}


Table A2. Cross-tabulation between inconvenience of top up and self-disconnection

\begin{tabular}{crrrr}
\hline \hline & & \multicolumn{3}{c}{ Self-disconnection } \\
\cline { 2 - 5 } & \multirow{2}{*}{ Inconvenience of top up } & 0 & 1 & Total \\
\hline & & 616 & 306 & 922 \\
& 1 & 45.46 & 22.58 & 68.04 \\
& & 203 & 230 & 433 \\
& & 14.98 & 16.97 & 31.96 \\
\hline \multirow{2}{*}{ Total } & 819 & 536 & 1,355 \\
& & 60.44 & 39.56 & 100 \\
\hline \hline
\end{tabular}

Notes: Pearson chi2 $(1)=48.9422(\mathrm{p}=0.000)$.

Table A3. Cross-tabulation between top up all year and self-disconnection

\begin{tabular}{lrrrr}
\hline & & \multicolumn{3}{c}{ Self-disconnection } \\
\cline { 3 - 5 } & & 0 & 1 & Total \\
\hline \multirow{3}{*}{ Top up all year } & 0 & 732 & 499 & 1231 \\
& \multirow{3}{*}{1} & 53.59 & 36.53 & 90.12 \\
& & 96 & 39 & 135 \\
& \multirow{2}{*}{ Total } & 7.03 & 2.86 & 9.88 \\
\hline \hline & & 828 & 538 & 1,366 \\
& & 60.61 & 39.39 & 100 \\
\hline
\end{tabular}

Notes: Pearson chi2 $(1)=6.9132(\mathrm{p}=0.009)$.

Table A4. Cross-tabulation between saving behaviour and self-disconnection

\begin{tabular}{crrrr}
\hline \hline & \multicolumn{3}{c}{ Self-disconnection } \\
\cline { 2 - 5 } & 0 & 0 & 1 & Total \\
\hline \multirow{3}{*}{ Saving Behaviour, redefined } & 507 & 316 & 823 \\
& 1 & $46.34 \%$ & $28.88 \%$ & $75.23 \%$ \\
& 1 & 154 & 117 & 271 \\
& & $14.08 \%$ & $10.69 \%$ & $24.77 \%$ \\
\hline \multirow{2}{*}{ Total } & 661 & 433 & 1094 \\
& $60.42 \%$ & $39.58 \%$ & $100 \%$ \\
\hline \hline
\end{tabular}

Notes: Pearson chi2 $(1)=1.9457(\mathrm{p}=0.163)$. The relation between saving behaviour and self-disconnection is not statistically significance.

Table A5. Cross-tabulation between spare cash and low-income

\begin{tabular}{crrrr}
\hline \hline & & \multicolumn{3}{c}{ Low income } \\
\cline { 2 - 5 } & & 0 & 1 & Total \\
\cline { 3 - 5 } & 0 & 312 & 258 & 570 \\
Spare cash, redefined & & $25.68 \%$ & $21.23 \%$ & $46.91 \%$ \\
& 1 & 400 & 245 & 645 \\
& & $32.92 \%$ & $20.16 \%$ & $53.09 \%$ \\
\hline \multirow{2}{*}{ Total } & 712 & 503 & 1215 \\
& & $58.6 \%$ & $41.4 \%$ & $100 \%$ \\
\hline \hline
\end{tabular}

Notes: Pearson chi2 $(1)=6.6079(\mathrm{p}=0.010)$. 


\section{Sample of question on saving plan choice}

The following questions relate to how the payment plan may work and we are looking for your thoughts on what would be the most beneficial / easy to use.

Before entering onto the payment plan, you would need to agree to a tailored quote detailing your consumption patterns and spend over the year - this would help you understand how you might manage the cost of your gas with different saving options that suit your lifestyle and income. Some of these options have been listed below and we'd like to know how these sound to you.

The following options are variants of the savings plan. We'd like to know how these saving plans A to E appeal to you. Please rate $1-5$ where 1 is not appealing and 5 is extremely appealing
1
23
45
Don't know

\section{A. Regular payments throughout year}

Based on the summary of your previous year's consumption, you agree to an equal weekly / monthly amount that you commit to paying through the year. Regular equal payments would cover your consumption throughout the year.

\section{B. Voluntary Savings Target}

You chose a target amount that you feel comfortable / confident in saving. You're responsible for meeting this target and it would be up to you whether or not you achieved your target each month. The credit you saved would be used to offset your winter consumption.

\section{Ad-hoc Extra Payments}

You make additional payments as and when you can afford to do so. You would not have to nominate a target for your savings but the more you saved, the more of your winter consumption would be offset.

\section{Summer Fixed Extra Payments}

You commit to additional fixed payments just during summer months. These additional payments would be calculated on the basis of your winter time gas consumption in the previous year. The extra payments would be used to cover your higher gas payments in the wintertime.

\section{E. Feedback on Consumption}

Without changing your monthly payment plan, you receive regular feedback in the summer about your average gas payments. For example: "Last year you spent $£ 20$ on gas between July and September and you spent $£ 120$ on gas between October and December".

From the options listed in the question above which savings plan would you prefer? Choose one option only:
A. Regular payments throughout year
B. Voluntary Savings Target
C. Ad-hoc Extra Payments
D. Summer Fixed Extra Payments
E. Feedback on Consumption
None of the above 


\section{Sample of question on goal achievement}

For the savings plan you selected in the question above, do you agree with the following statements? Please rate from 1 to 5, where 1 is Strongly Disagree and 5 is Strongly Agree.

I am interested

It would give me more control over my spend on gas

It would be a good reminder to save for my future spend on gas

It would stop me spending too much on things I don't need

It sounds complicated

Table A6. Distribution of goal achievement questions

\begin{tabular}{|c|c|c|c|}
\hline Answer & Freq. & $\begin{array}{r}\text { Percent } \\
\text { over all } \\
\text { variables }\end{array}$ & $\begin{array}{r}\text { Percent } \\
\text { over } \\
\text { groups }\end{array}$ \\
\hline \multicolumn{4}{|l|}{ Goal achievement } \\
\hline \multicolumn{4}{|l|}{ High } \\
\hline I usually achieve my goals & 409 & 35.2 & 58.8 \\
\hline $\begin{array}{l}\text { I usually set-up weekly or monthly goals that I wish to achieve and I } \\
\text { usually achieve my goals }\end{array}$ & 287 & 24.7 & 41.2 \\
\hline Total & 696 & 59.9 & 100.0 \\
\hline \multicolumn{4}{|l|}{ Medium } \\
\hline I usually set-up weekly or monthly goals that I wish to achieve & 184 & 15.8 & 52.9 \\
\hline I have difficulties in completing a task that requires organization & 31 & 2.7 & 8.9 \\
\hline I usually avoid or delay a task that requires a lot of thinking & 68 & 5.9 & 19.5 \\
\hline $\begin{array}{l}\text { I usually set-up weekly or monthly goals that I wish to achieve and I have } \\
\text { difficulties in completing a task that requires organization }\end{array}$ & 7 & 0.6 & 2.0 \\
\hline $\begin{array}{l}\text { I usually set-up weekly or monthly goals that I wish to achieve and I } \\
\text { usually avoid or delay a task that requires a lot of thinking }\end{array}$ & 21 & 1.8 & 6.0 \\
\hline $\begin{array}{l}\text { I have difficulties in completing a task that requires organization and I } \\
\text { usually achieve my goals }\end{array}$ & 5 & 0.4 & 1.4 \\
\hline $\begin{array}{l}\text { I usually avoid or delay a task that requires a lot of thinking and I usually } \\
\text { achieve my goals }\end{array}$ & 32 & 2.8 & 9.2 \\
\hline Total & 348 & 30 & 100.0 \\
\hline \multicolumn{4}{|l|}{ Low } \\
\hline I don't usually achieve my goals & 34 & 2.9 & 29.1 \\
\hline $\begin{array}{l}\text { I usually set-up weekly or monthly goals that I wish to achieve and I don't } \\
\text { usually achieve my goals }\end{array}$ & 17 & 1.5 & 14.5 \\
\hline $\begin{array}{l}\text { I have difficulties in completing a task that requires organization and I } \\
\text { don't usually achieve my goals }\end{array}$ & 17 & 1.5 & 14.5 \\
\hline $\begin{array}{l}\text { I have difficulties in completing a task that requires organization and I } \\
\text { usually avoid or delay a task that requires a lot of thinking }\end{array}$ & 27 & 2.3 & 23.1 \\
\hline $\begin{array}{l}\text { I don't usually achieve my goals and I usually avoid or delay a task that } \\
\text { requires a lot of thinking }\end{array}$ & 18 & 1.6 & 15.4 \\
\hline I don't usually achieve my goals and I usually achieve my goals & 4 & 0.3 & 3.4 \\
\hline Total & 117 & 10.1 & 100.0 \\
\hline
\end{tabular}


Table A7. Medium Goal Achievement: mean characteristics

\begin{tabular}{|c|c|c|c|c|c|}
\hline Variable & Obs & Mean & Std. Dev. & Min & Max \\
\hline Female & 348 & 0.72 & 0.45 & 0 & 1 \\
\hline \multicolumn{6}{|l|}{ Age } \\
\hline 21 and Under & 348 & 0.00 & 0.05 & 0 & 1 \\
\hline 22 to 34 & 348 & 0.29 & 0.45 & 0 & 1 \\
\hline 35 to 44 & 348 & 0.24 & 0.43 & 0 & 1 \\
\hline 45 to 54 & 348 & 0.39 & 0.49 & 0 & 1 \\
\hline 55 to 64 & 348 & 0.22 & 0.42 & 0 & 1 \\
\hline 65 and Over & 348 & 0.07 & 0.26 & 0 & 1 \\
\hline Top-up all year & 348 & 0.09 & 0.28 & 0 & 1 \\
\hline \multicolumn{6}{|l|}{ Income } \\
\hline Low & 287 & 0.45 & 0.50 & 0 & 1 \\
\hline Medium & 290 & 0.40 & 0.49 & 0 & 1 \\
\hline High & 290 & 0.14 & 0.35 & 0 & 1 \\
\hline \multicolumn{6}{|l|}{ Education } \\
\hline None & 321 & 0.12 & 0.32 & 0 & 1 \\
\hline Basic & 321 & 0.38 & 0.49 & 0 & 1 \\
\hline Medium & 321 & 0.36 & 0.48 & 0 & 1 \\
\hline High & 321 & 0.15 & 0.35 & 0 & 1 \\
\hline
\end{tabular}


Table A8. Seemingly Unrelated Bivariate Probit

\begin{tabular}{|c|c|c|}
\hline $\begin{array}{r}\text { Seemingly Unrelated } \\
\text { Bivariate Probit }\end{array}$ & $\begin{array}{c}\text { Dep. Var.: Emergency } \\
\text { credit }\end{array}$ & $\begin{array}{c}\text { Dep. Var.: } \\
\text { Self-disconnection }\end{array}$ \\
\hline \multicolumn{3}{|l|}{ Age } \\
\hline 35 to 44 & $\begin{array}{l}.152 \\
(.234)\end{array}$ & $\begin{array}{l}-.248 \\
(.229)\end{array}$ \\
\hline 45 to 54 & $\begin{array}{l}.077 \\
(.224)\end{array}$ & $\begin{array}{l}-.207 \\
(.220)\end{array}$ \\
\hline 55 to 64 & $\begin{array}{l}-.007 \\
(.234)\end{array}$ & $\begin{array}{l}-.214 \\
(.230)\end{array}$ \\
\hline Over 65 & $\begin{array}{l}-.256 \\
(.270)\end{array}$ & $\begin{array}{l}-.452 * \\
(.274)\end{array}$ \\
\hline Female & $\begin{array}{l}-.003 \\
(.102)\end{array}$ & $\begin{array}{l}.022 \\
(.102)\end{array}$ \\
\hline Education & & \\
\hline Medium & $\begin{array}{l}.136 \\
(.103)\end{array}$ & $\begin{array}{l}.055 \\
(.103)\end{array}$ \\
\hline Higher & $\begin{array}{c}.055 \\
(.141)\end{array}$ & $\begin{array}{c}.017 \\
(.139)\end{array}$ \\
\hline Income & & \\
\hline Medium & $\begin{array}{c}.324 * * * \\
(.105)\end{array}$ & $\begin{array}{l}-.003 \\
(.104)\end{array}$ \\
\hline High & $\begin{array}{r}.162 \\
(.136)\end{array}$ & $\begin{array}{l}-.076 \\
(.138)\end{array}$ \\
\hline Household adults & $\begin{array}{l}.080 * \\
(.047)\end{array}$ & $\begin{array}{c}.069 \\
(.046)\end{array}$ \\
\hline Saving behavior & $\begin{array}{c}-.343 * * * \\
(.110)\end{array}$ & $\begin{array}{c}.027 \\
(.111)\end{array}$ \\
\hline Top up all year & $\begin{array}{c}-.490 * * * \\
(.156)\end{array}$ & $\begin{array}{c}-.441 * * * \\
(.170)\end{array}$ \\
\hline Inconvenience of top up & $\begin{array}{c}.042 \\
(.103)\end{array}$ & $\begin{array}{c}.398 * * * \\
(.100)\end{array}$ \\
\hline Goal Achievement & & \\
\hline Low & & $\begin{array}{l}.265^{*} \\
(.154)\end{array}$ \\
\hline Medium & & $\begin{array}{c}.288 * * * \\
(.103)\end{array}$ \\
\hline Constant & $\begin{array}{l}.038^{\mathrm{a}} \\
(.264)\end{array}$ & $\begin{array}{l}-.413^{\mathrm{a}} \\
(.266)\end{array}$ \\
\hline Rho & $\begin{array}{l}.258 \\
(.058)\end{array}$ & \\
\hline $\begin{array}{r}\text { Likelihood-ratio test of } \\
\text { rho }=0 ; \text { Prob }>\text { chi } 2\end{array}$ & 0 & \\
\hline Wald $\operatorname{chi} 2(28)$ & 82.12 & \\
\hline Prob $>$ chi 2 & 0 & \\
\hline Number of observations & 787 & \\
\hline
\end{tabular}

Notes: Coefficient estimates are reported. Standard errors are in parenthesis. ***,**,* stand for 1,5 , and 10 percent significant levels, respectively. Age under 22 and Age to 34, none and low education, low income and high goal achievement were used as reference categories. 